\title{
La Italia de Rubén Darío, Enrique Gómez Carrillo y José Carlos Mariátegui, 1900-1921
}

\author{
The Italy of Rubén Darío, \\ Enrique Gómez Carrillo and \\ José Carlos Mariátegui, 1900-1921
}

\author{
Rogelio de la Mora $V^{*}$ \\ (D) https://orcid.org/0000-0001-9307-5615 \\ Instituto de Investigaciones Histórico-Sociales \\ Universidad Veracruzana, México \\ rdelamora@uv.mx
}

Resumen: El presente artículo examina las relaciones de Rubén Darío (18671916), Enrique Gómez Carrillo (1873-1927) y José Carlos Mariátegui (18941930) con el contexto intelectual y cultural italiano durante sus estancias respectivas en la península itálica. Específicamente, el análisis se enfoca en el caso de los dos primeros, uno a través de los testimonios de su estancia en Italia; el segundo mediante sus escritos y sus vínculos directos con destacados decadentistas y vanguardistas; respecto de Mariátegui, sobre las circunstancias en las que escribe sus Cartas de Italia, en vinculación con L'Ordine Nuovo, dirigido por Antonio Gramsci, y con la presencia de Piero Gobetti. Este texto,

* Doctor en Historia por la Escuela de Estudios Superiores en Ciencias Sociales de París (eHEss, por sus siglas en francés). Sus líneas actuales de investigación se centran en el trabajo intelectual, pensamiento y modernidad en América Latina, siglos XIX-XX.

cómo citar: Mora V., R. de la (2021). La Italia de Rubén Darío, Enrique Gómez Carrillo y José Carlos Mariátegui, 1900-1921. Secuencia (110), e1765. Dor: https://doi.org/10.18234/secuencia.v0i110.1765

cC Esta obra está protegida bajo una Licencia Creative Commons Atribución-NoComercial 4.0 Internacional. 
que recurre en gran parte a producciones historiográficas recientes, concluye al evidenciar la interacción de los actores con el componente histórico.

Palabras clave: contexto intelectual; Italia; Rubén Darío; Enrique Gómez Carrillo; José Carlos Mariátegui.

Abstract: This article examines the relationship between Rubén Darío (18671916), Enrique Gómez Carrillo (1873-1927) and José Carlos Mariátegui (18941930) and the Italian intellectual and cultural context during their respective stays in Italy. In the case of the first two writers, the article focuses on the former's accounts of his stay in Italy and the latter's writings and direct links with prominent Decadentists and avant-garde artists. In the case of Mariátegui, it examines the circumstances in which he wrote Cartas de Italia, in connection with L'Ordine Nuovo, directed by Antonio Gramsci, and with the presence of Piero Gobetti. The text, which draws heavily on recent historiographic productions, concludes by highlighting the interaction of the actors with the historical component.

Keywords: intellectual context; Italy; Rubén Darío; Enrique Gómez Carrillo; José Carlos Mariátegui.

Recibido: 1 de julio de 2019 Aceptado: 29 de mayo de 2020

Publicado: 12 de mayo de 2021

I

nteresa particularmente aquí examinar las relaciones de tres autores en la cresta de la ola de su tiempo, Rubén Darío (1867-1916), Enrique Gómez Carrillo (1873-1927) y José Carlos Mariátegui (1894-1930), con la atmósfera cultural e intelectual italiana (autores, actores y discursos), durante sus estancias respectivas en Europa, si bien en circunstancias y momentos diferentes. De manera más específica, nos detendremos en el caso de Rubén Darío y Enrique Gómez Carrillo, uno a través de los testimonios de su recorrido por diferentes ciudades de Italia (1900); el segundo mediante sus viajes y crónicas, así como sus vínculos directos con destacados artistas y escritores decadentistas y vanguardistas. Ambos representantes del modernismo, vivirán la mayor parte de su estadía europea en Francia; Gómez Carrillo muere allí. En cuanto a Ma- 
riátegui, quien durante su estadía europea vive la mayor parte del tiempo en Italia (1919-1922), la atención estará puesta en su recepción de los contenidos de la prensa en Turín, específicamente en L'Ordine Nuovo (1 de mayo 1919-30 de octubre de 1922), dirigido por Gramsci, de manera particular las colaboraciones de Piero Gobetti. Con tal propósito, hemos consultado la información contenida en el Centro Studi Piero Gobetti en Turín, y recurrido a colecciones digitalizadas disponibles.

De los tres -en la ocasión- corresponsales de prensa, los dos centroamericanos se conocen en Guatemala y ligan una amistad -cierto, fluctuanteque perdurará a lo largo de sus vidas. ${ }^{1}$ Estamos en 1890: Darío (23 años) dirige entonces el periódico El Correo de la Tarde, en el cual trabaja como periodista Gómez Carrillo (17 años). En la misma ciudad de Guatemala, la imprenta La Unión publica ese año la segunda edición corregida y aumentada de Azul..., la emblemática obra fundacional del modernismo. De esta juvenil experiencia, Gómez Carrillo escribirá más tarde: "A él le debo, en efecto, la primera lección de fecunda belleza. Él me enseñó a comprender que hay en el saber escribir algo que es más que saber, y algo que es más que escribir [...] Azul... fue el evangelio que me hizo sentir que, por encima de todo, el arte es una religión" (Ulner, 1974, p. 19). En poco tiempo, Gómez Carrillo emigrará a Europa y será a la prosa lo que Darío a la poesía en el modernismo.

Por su parte, José Carlos Mariátegui visita París en dos ocasiones, al inicio y al final de su estancia italiana (1919-1923); para entonces, Darío ya había muerto y Gómez Carrillo pasaba la mayor parte de su tiempo en Niza. Pero si en la Ciudad Luz no coinciden, desde sus años juveniles lee y admira la obra de Rubén Darío, a quien considera "el más grande poeta de España y de América”. ${ }^{2}$ En cambio, Mariátegui es menos indulgente con Gómez Carrillo; no le perdona lo que él considera ligereza y superficialidad en sus escritos, así como tampoco sus concesiones a la industria cultural. No obstante, como tantos otros jóvenes de su generación, Mariátegui había ingresado al mundo de las letras a través de la puerta abierta por los cronistas -quienes mediante sus publicaciones difundían lo más granado del pensamiento europeo e hispanoamericano de la época-, entre los cuales Gómez Carrillo era un maestro en (2016).

${ }^{1}$ Sobre esta relación amistosa, fluctuante tras las bambalinas, véase Fernández Ordoñez

${ }^{2}$ José Carlos Mariátegui (Juan Croniqueur), "Luisa Morales Macedo, artista admirable", El Tiempo, 23 de septiembre de 1916, p. 2. 
su género (Chang-Rodríguez, 1982, p. 198). Con motivo del fallecimiento del escritor guatemalteco, el pensador peruano publicará un artículo en el que, en clave vanguardista, rinde cuentas y "tuerce el cuello" al cisne de la crónica modernista, afirmando que el "príncipe de la crónica" había sido un "cortesano de los gustos de su clientela [...] carece de opiniones. Reemplaza el pensamiento con impresiones que casi siempre coinciden con las del público.”

Rubén Darío se encuentra en España como corresponsal del diario La Nación de Buenos Aires en el que labora desde 1889, cuando recibe y acepta de los editores la invitación para trasladarse a la capital gala, y como corresponsal cubrir la Exposición Universal de París (14 de abril-2 de noviembre). De estas jornadas, Darío envía un total de doce crónicas sobre diversos aspectos, que van desde la inauguración de la Exposición y "la psicología de los visitantes", hasta los pabellones de los países invitados, tales como "La casa de Italia" y "Los anglosajones”, los cuales La Nación publica entre abril y septiembre de ese mismo año. ${ }^{4}$ Es en este contexto que Darío partirá rumbo a la península itálica.

Con el apoyo prácticamente sin restricciones, a no ser en el aspecto financiero, de Emilio Mitre, director de La Nación, Darío tiene la libertad de proponer el lugar de destino, así como la duración y el propósito del viaje. ${ }^{5}$ Durante su recorrido por la casa de Italia, su acompañante, el poeta y novelista nietzscheano de origen napolitano Hugues Rabell (1867-1905), comentó que para gustar de Italia era preciso ir a Italia. Tal consideración, aunada al hecho de que esa tierra amada por los artistas "era mi sueño deseado [...] para todo poeta y para todo artista el viaje a Italia, el tradicional país del arte, es un complemento indispensable en su vida" (Darío, 1915, p. Lx), sin mucho pensarlo, lleva al poeta nicaragüense a reconfirmar su disposición para cumplir con su misión en el corazón de la historia del patrimonio cultural y artístico europeo. El objetivo y la justificación se definen enseguida: informar a los de 1927 .

${ }_{3}^{3}$ José Carlos Mariátegui, "El príncipe de la crónica", Variedades de Lima, 3 de diciembre

${ }^{4}$ Fechas 30 de abril, 1, 23, 28 y 29 de mayo; 4 y 5 de junio; 9 de julio; 1,16 y 29 de agosto; 6,15 y 24 de septiembre. Un análisis de las colaboraciones de Darío para La Nación se encuentra en Colombi (1997).

${ }^{5}$ Véase Teodosio Fernández (2016). 
lectores del diario argentino sobre el Jubileo o Año Santo en El Vaticano. Por su simbolismo, uno de los acontecimientos más importantes de la Iglesia católica romana, cuya ceremonia de inauguración -la apertura por el Papa León XIII de la Porta Sancta de la Basílica de San Pedro- había sido el 1 de agosto. Dicho evento sigue una secuencia tradicional significativa en el mundo católico, enraizada en la tradición hebraica, fundada en la redención, y que, en esta ocasión, tiene como precedente inmediato el Año Santo de 1825.

El itinerario por el que se inclina Darío es el del Grand Tour, especie de viaje ritual de estudio o esclarecimiento para jóvenes en transición a la edad adulta pertenecientes a familias "acomodadas", en boga a partir de las primeras décadas del siglo XVIII. Podría haber variantes, pero tenía que iniciar en París y entrar a Italia a través de los Alpes: Turín, Milano o Venecia eran los grandes ejes del norte de la península. Así que desde el departamento que en el Faubourg Montmartre de París comparte con Gómez Carrillo, Darío emprende su camino rumbo a la "divina península", desplazándose a la cercana Gare du Nord para abordar el tren con dirección a la capital del Pieamonte (11 de septiembre). En uno de los compartimentos de este invento tecnológico mayor, pronto dejará atrás la "dulce Francia", al internarse por las faldas caprichosas de la cadena montañosa de los Alpes que desfila por su ventana y le hace recordar Los Andes. Al día siguiente, a lo lejos, la silueta de la basílica de Superga le anuncia su arribo inminente a Turín, "de nombre sonoro, noble ciudad". Una vez instalado en su hotel, recorre las galerías, las plazas, la Via Roma, y enfrente de la Piazza Castello, asiste a un espectáculo en el teatro Giardino Romano, cuyo inmueble -comenta, sin más detalles- se encuentra "deteriorado". El filósofo Federico Nietzsche, fallecido en Weimar días antes (25 de agosto) y quien durante su última estadía en Turín (21 de septiembre 1888-9 de enero 1889) se hospedaba muy cerca de allí, en su correspondencia describe este local recién abierto como un "pequeño teatro simpático", el cual, en verano, funcionaba también un café-chantant a la intemperie, el Giardino Caffè Romano, frente al cual solía detenerse a comer helados y escuchar La Mascotte de Edmond Audran (Verrecchia, 1978, p. 98). Es a una de estas funciones a la que Darío asiste probablemente.

La próspera ciudad, "práctica y vigorosa, de trabajo y esfuerzo", le permite al poeta conocer esa otra faceta moderna y boyante de la península. En un país esencialmente agrícola, la presencia de las industrias eléctrica, química, metalúrgica y mecánica, entre las cuales la de mayor relevancia es la del sector automovilístico -resumido en la Fabbrica Italiana Automobili Torino 
(FIAT), fundada en 1889-, convertía rápidamente a la ciudad en el corazón industrial del país y, por extensión, en el de los "productores", es decir, en la capital del moderno proletariado italiano. Aunque su pabellón en la Exposición Universal de París había sido una especie de preliminar, de botón de muestra, es probable que Darío estuviera enterado de la inauguración del primer establecimiento productivo de la FIAT Corso Dante, en marzo de ese mismo año, situado a poca distancia del castillo medieval que visita en esos días, hecho que consigna en su diario. Darío parece predecir lo que ocurrirá allí dos décadas más tarde, cuando asienta: "Después sabréis de sus ricas y florecientes industrias". Lo que sucederá en la sede de esa poderosa empresa dos décadas más tarde, el movimiento de los consejos de fábrica, es un punto que abordaremos en el tercer apartado de este escrito.

En aquel el momento, Darío no oculta su contrariedad al constatar la omnipresencia de monumentos e inmuebles históricos, relacionados mayoritariamente con la dinastía Saboya: "Por todas partes estos políticos, estos generales, estos príncipes, me aguan la fiesta ideal que busca aquí mi espíritu. Estos políticos son demasiado conocidos para que interesen a quien buscan en Italia, sobre todo en el reino de la belleza, de la poesía del Arte [...] Aquí todo es Saboya. No hay monumento, no hay vía, no hay edificio que no os hable de la ilustre casa" (Darío, 1900, pp. 55-98).

Es difícil entender el porqué un observador de ojo severo como Darío omite en su diario la existencia de lo que se había convertido ya en el símbolo por excelencia de Turín y pronto de Italia, el edificio de albañilería más alto del mundo, de 167 metros de altura, una verdadera acrobacia vertiginosa de columnas fuertes y dinámicas, situada a poca distancia de la Pinacoteca y otros sitios que en su diario registra, inició su construcción en 1867 y fue inaugurada en su última fase en 1889: la Mole Antonelliana. Imposible de escapar para la mirada hasta del visitante más inadvertido, puede contemplarla desde cualquier punto geográfico de la ciudad. Esta obra había causado una gran impresión al autor de El nacimiento de la tragedia: "el edificio más genial que tal vez ha sido construido por un absoluto impulso hacia lo alto, no me recuerda a nadie más que a Zaratustra. Lo he bautizado 'Ecce homo' y lo he circundado en el espíritu con un inmenso espacio libre". ${ }^{6}$ Para disfrutar de la

${ }^{6}$ Carta a su amigo Heinrich Kolselitz, fechada el 30 de octubre de 1888 (Nietzsche, 2008). Para Nietzsche, la vida buena es ascendente, mientras que la vida mala es descendente. De ahí el elogio alusivo al impulso hacia lo alto. 
visualización plástica de su Zaratustra, el filósofo trasgresor gustaba de sentarse a admirarla desde alguna de las cafeterías de las proximidades; transposición arquitectónica que, quizá voluntariamente o por cuestiones de tiempo, permanece invisible a los ojos del poeta amante del arte y de la literatura.

Si los monumentos que proliferan en el centro histórico carecen de elementos para atraer su atención, en cambio Rubén Darío se encuentra fascinado en el interior de la Pinacoteca, frente a la riqueza contenida en obras clásicas y académicas de los maestros y otros artistas de diferentes épocas. En este andar, se detiene para presentar y comentar, sala por sala, algunas de las obras de creadores que admira: Macrino d'Alba, Defendente Ferrari, Sodoma, Boticelli, Tiziano, Donatello, Van Dyck, Brueghel, Holbein, Velázquez, Murillo, Ribera, Sánchez Coello, entre muchos otros. Al final, renuncia a la ambiciosa tarea de transmitir en palabras todo lo que sus sentidos perciben: "Imposible observar tanta y tanta obra meritoria" (Darío, 1901, p. 7).

A falta de información proveniente de fuentes primarias, cedamos la palabra a Giusseppe Bellini (1982): "Toda la obra poética de Darío, y gran parte de su prosa, está llena de la presencia de una Italia ideal, símbolo de la belleza, la gloria y el genio. Cuando Darío realiza, en 1900, su anhelado viaje a Italia, las primeras páginas de su diario revelan eficazmente la hondura de su presencia de este país en su formación cultural y en su espíritu” (p. 367).

En realidad, en las crónicas de Darío se entrecruzan -complementándose-dos tipos de discursos: el interpretativo, que es el de la Italia ideal, emanando de la subjetividad y el simbolismo, por una parte, $y$, por otra, el informativo, el de la Italia en su cotidianidad, tal como el escritor viajero la percibe de manera objetiva, natural y espontánea. Esta forma de relato es una constante en sus contenidos, incluido el de esta primera escala, la cual concluye en la estación Porta Nuova, donde el "caballo de hierro" lo conduce a galope con destino a Génova, el 17 de septiembre. Ve huir el paisaje mientras piensa que Torino "ha de ser siempre triste", coincidiendo en ello con los testimonios de otros viajeros que lo han precedido, tales como Flaubert. ${ }^{7}$ Al final de su trayecto, entra a destino por San Pietro d'Arena, conjunto de conventi-

${ }^{7}$ Flaubert describe a Turín como la ciudad más tediosa del mundo, al igual que el Marqués de Sade, quien estuvo allí en dos ocasiones (Massimo, 2007). Esta sensación de melancolía, de tristeza, está presente en los simbolistas y es recurrente en la literatura modernista. Rubén Darío la había reflejado en "Canción de carnaval" (en Prosas profanas y otros poemas, 1896), y volverá a hacerlo en "Melancolía" (en Cantos de vida y esperanza, 1905). El "sol negro", el "mal del siglo", es el signo distintivo del artista. El mal perdura, sus imágenes y sus formas cambian. 
llos que le recuerdan el barrio de Boca. En el núcleo urbano, eslabona diversas actividades que en el camino ha programado: divisa la urbe desde la cima del Righi y visita el cementerio, la catedral, el palacio Rosso y el palacio Bianco, pero pronto reconoce que: "No puedo, dado el plan de este diario, ni citar todo lo que me interesa" (Darío, 1900, p. 72).

En Pisa, donde lo encontramos el 20 de septiembre, describe e interpreta, en un estilo que en ocasiones puede ser telegráfico, los tesoros artísticos o arquitectónicos que su mirada capta en el Baptisterio, el Campanile, la catedral de San Lorenzo, la Piazza del Duomo, la Cartuja de Calci. Las simples observaciones se yuxtaponen con relatos más elaborados, cargados de emoción o de referencias históricas o literarias, o ambos a la vez, a los que envuelve con imágenes poéticas. Para comprender el lugar donde se encuentra y sus antípodas, el bardo tampoco pierde la oportunidad de examinar el sentido y la idea del viaje (la distinción entre un (badaud y un flâneur, por ejemplo), consustancial a la escritura y a la lectura, y, en su caso, homologada a la melopea. ${ }^{8}$

En su viaje hacia Roma (27 de septiembre), realiza una breve escala en Livorno para visitar, siempre "rápidamente, en un vuelo artístico", el Santuario della Madonna di Montenero, los astilleros y el Palazzo Mansi; luego, retoma su camino. Parecida a un enorme museo a cielo abierto y con una historia de más de 2700 años, la Ciudad Eterna se ofrece al descubrimiento diferente de Darío, del 3 de octubre al 1 de noviembre. Las calles y las avenidas son surcadas por fieles provenientes de todos los rincones del mundo, atraídos por el toque de campanas de las festividades del Jubileo. En este ambiente de devoción, Darío se entrega a la tarea de visitar, tomar notas, redactar y enviar por correo a La Nación sus propias apreciaciones de los sitios imprescindibles: el Foro, el Coliseo, las Catumbas, Villa Borghese, el Pincio, las basílicas de San Pedro, San Giovanni in Laterano y Santa Maria Maggiore.

Podemos conocer parte de estos episodios gracias al testimonio del entonces ministro de Ecuador en Italia (1898-1903), novelista, panfletista político y poeta colombiano de retórica dannunziana, exaltada y extravagante, José María Vargas Vila (1860-1933), a quien Darío había conocido en ocasión de la Exposición Universal de París, y con quien convive durante un par de días

${ }^{8}$ Como lo atestigua Vargas Vila, Darío era ya por estas fechas un consumidor consuetudinario de bebidas alcohólicas. Vargas (1917, p. 30). 
(18 y 19 de septiembre). ${ }^{9}$ Sea porque él mismo estuvo presente o por haber recabado información de su asistente Ramón Palacio Viso, Vargas Vila relata con ironía momentos recurrentes de espontánea exaltación en que solía sumirse el poeta -oscuros a causa de su intensidad y apenas comprensibles para quien se ha forjado en el radicalismo libertario, anticlerical e individualista-. Este escritor, quien se jactaba de nunca haberse arrodillado ante un mortal y que consideraba al Papa como representante de la enemistad mortal contra la vida, cuenta que durante las festividades del Año Santo en la Basílica de San Pedro, cuando "el grito delirante de las multitudes" anunciaba el paso inminente del Papa, súbitamente el poeta estalló en lágrimas y, fusionándose con el sentimiento del "alma colectiva" (Gustave Le Bon) que allí palpitaba, se arrodilló cuando los otros se arrodillaban, para, finalmente, quedar "postrado en una especie de hipnósis”. En otra ocasión, encontrándose en Santa Maria Maggiore, "siguió una procesión cirio en mano y se licuó en lágrimas, oyendo las pláticas de un fraile franciscano". Y, en San Giovanni Laterano -nos sigue narrando Vargas Vila- sin premeditación, súbitamente Darío acudió al llamado de la penitencia de un sacerdote que a su paso predicaba; se aproximó, juntó las manos y se arrodilló, desplazándose así hasta el confesionario. En otro pasaje de su biografía, el escritor colombiano, en un esfuerzo por comprender tales escenas, dirá: "los yacimientos vírgenes de aquella alma, se mostraron a mis ojos, en el raro esplendor de sus riquezas" (Vargas Vila, 1917, pp. 24-25).

Durante el recorrido ferroviario de los más de $200 \mathrm{~km}$ de distancia que separan Roma de Nápoles, el paisaje viene al encuentro de Darío antes de salir hacia allá, el 11 de noviembre. En esta ciudad, que en su Grand Tour italiano Stendhal califica como "el lugar más bello del universo", el poeta cronista, entre evocaciones de Virgilio y Séneca, deja constancia de su visita a Capri, Sorrento, Castellammare, Pozzuoli, Posillipio y la Cartuja de San Martino. En su viaje de retorno a París se detiene en Florencia, en cuyos sitios consagrados (Palazzo Vecchio, Museo degli Uffizi, entre otros) contempla "con emoción casi dolorosa" la belleza del arte sublime. Esta perplejidad frente a la magnificencia de las obras de arte que puede ir acompañada de malestar físi-

9 Si bien se conocieron personalmente en París, su relación, marcada por la enemistad, data de 1894, así como rememora Vargas Vila en la biografía, que le consagra a Rubén Darío, un año después de su fallecimiento (1917). En esta biografía, que es también un ensayo panegírico pletórico de imágenes, el escritor colombiano desglosa las circunstancias de su encuentro en Roma y discurre sobre la estrecha amistad que lo uniría con el admirado vate nicaragüense en años subsecuentes. 
co (taquicardia, vértigo, alucinaciones), será conocida posteriormente como "síndrome de Stendhal", por el éxtasis que este escritor francés experimenta en la basílica de la Santa Croce, en ocasión de su primera visita a Italia. ${ }^{10}$

Luego de la ciudad de los canales y de las góndolas, Darío visitó Milán, desde donde tomó el tren de regreso a París. Cerrará este fin de siglo mordiendo a un siglo nuevo, del cual tomará algunos rasgos, con sus reflexiones del año nuevo parisiense ("Noel parisiense" y otros más), publicadas en $L a$ Nación y, posteriormente, incorporadas con el título de Diario de Italia en Peregrinaciones, en 1901. En su prólogo, Justo Sierra (1901) sintetiza el estado de ánimo con que el poeta emprende, pero también culmina, su misión periodística en el Bel Paese. Escuchémoslo: "Rubén Darío entró a Italia como se debe entrar, con la devoción ingenuamente pagana de un católico, dispuesto a arrodillarse en los Calvarios convertidos en Tabores, ante los Cristos-Apolos, ante las Madonas-lirios de Angélico, nardos de Boticelli, rosas de ternura de Rafael, de dolor de Dolci, de vida de Andrea del Sarlo y de cielo de Bellini."

A poco de cumplir 18 años, por intermediación de Rubén Darío (si bien en sus memorias, Carrillo afirma que por méritos propios), Carrillo fue enviado a España por el presidente Manuel Lisandro Barillas (1886-1892), con el objetivo de adquirir experiencia y más amplios conocimientos en Europa. En 1891, antes de llegar al país ibérico, visita París, ciudad donde finalmente se instala -desestimando las instrucciones de su mecenas, que lo quería en Madrid-y da inicio su vida de escritor, al publicar su primer libro, Esquisses (1892), seguido de Sensaciones de arte (1893), con prefacio de Salvador Rueda. Pronto se convierte en uno de los puntales refinados del modernismo y, si bien a veces irreverente con escritores e intelectuales españoles, el desarrollo de esta corriente en España se debió en gran medida a su pluma. Sus crónicas, en general gratas al gusto del público por su amenidad, serán conocidas a través del suplemento literario de El Imparcial. En el universo de las literaturas, sus principales inspiradores son Victor Hugo, Gustavo Flaubert, Paul Verlaine, los

${ }^{10}$ Darío (1904) volverá tanto a esta ciudad como a Venecia, en mayo de 1904, ocasión en la cual escribirá un artículo sobre cada una de ellas, mismos que serán incluidos en la segunda parte de su Tierras solares (pp. 81-192). 
hermanos Goncourt. Darío, que también será criticado por el tono afrancesado de sus escritos (pero siempre "en las líneas perfectamente castellanas") ${ }^{11}$ dirá de él que "es un escritor francés que se traduce a sí mismo". ${ }^{2}$

En París, Gómez Carrrillo entrevista y frecuenta a autores que llenan con su fama el mundo de las letras, como Moréas, Verlaine, Tailhade, D’Annunzio, Marinetti y Maeterlinck. Entre las numerosas revistas que Gómez Carrillo fundó y dirigió en el trayecto de su vida destacan: El Nuevo Mercurio (Barcelona, 1907) ${ }^{13}$ y Cosmópolis (Madrid, 1919-1921), publicación atenta a las nuevas corrientes artísticas americanas y europeas, que liga modernismo con vanguardia, en cuya nómina figura gran cantidad de colaboradores ocasionales o permanentes latinoamericanos como Alfonso Reyes, Gabriela Mistral, Jorge Luis Borges, Pedro Henríquez Ureña, Xavier Villaurrutia y Manuel Maples Arce.

De este último, Gómez Carrillo publica en las columnas de Cosmópolis "Esos poemas eléctricos", en octubre de 1921. De hecho, el manifiesto del movimiento artístico literario de vanguardia, Estridentismo, será publicado tres meses más tarde en Actual. Hoja de vanguardia, núm. 1, en la ciudad de México. Texto en el cual el autor agradece explícitamente a los escritores que lo inspiran: Marinetti, Renée Dunan, Rafael Lasso de la Vega, entre otros. Posteriormente, en Soberana juventud (1967), el poeta mexicano recordará que a raíz de la publicación de su poema en Cosmópolis, recibe de Marinetti sus manifiestos futuristas, así como monografías ilustradas de los pintores involucrados en el movimiento, tales como Umberto Boccioni, Gino Severini y Ardengo Soficci. La revista dirigida por el escritor guatemalteco sirve de puente a esta transferencia cultural y al ejercicio vanguardista fecundado por el movimiento artístico, literario y musical italiano más importante de inicios del siglo xx.

Uno de los aspectos poco conocidos del escritor guatemalteco es su desempeño en el frente italiano -Verona y Milán-como corresponsal del diario El Liberal de Madrid, cuyos envíos eran publicados también en La Nación de Buenos Aires, entre finales de 1914 e inicios de 1915. Estos artículos serán reunidos y editados posteriormente en forma de libro en la capital española: Campos de batalla y campos de ruina, bajo el sello de Mundo Latino, en 1922.

${ }^{11}$ Juan Varela, "A manera de prólogo" (Darío, 1900).

${ }^{12}$ Citado en el prólogo a Enrique Gómez Carrillo (1925).

${ }^{13}$ En la que colaboran o son traducidos Marinetti, Max Nordau, Rubén Darío, Miguel de Unamuno, Jean Moréas, Salvador Rueda, Amado Nervo, Francisco García Calderón, Santos Chocano, entre otros. 
Como posteriormente Antoine de Saint-Exupéry cubriendo la guerra civil española, su papel de reportero consistía esencialmente en colectar información y redactar reportajes en el corazón de la acción, los cuales posteriormente eran enviados y difundidos en la prensa. En sus testimonios de primera mano propone al gran público su experiencia personal de la guerra, la cual él vive de cerca cotidianamente: sus impresiones, visiones y sentimientos. En su misión de informar, de dar cuenta de los hechos relativos al conflicto militar, el viaje que Gómez Carrillo realizó en Italia se redujo básicamente a los frentes de guerra, expuesto en permanencia a los peligros de la guerra misma. La peculiar coyuntura bélica le impedía dejarse seducir por las batallas del vagabundeo y el gran arte a la vuelta de cada esquina. No obstante, los escritos de esta etapa de su vida contribuirán a mostrar su faceta de periodista que busca la información precisa y exhaustiva, muy alejada de su fama de bohemio y de frívolo, subrayada por Mariátegui, como veremos más adelante.

Es un lugar común afirmar que, en el posromanticismo, Gabriele D’Annunzio fue un modelo para la literatura hispanoamericana, pues tempranamente será no sólo estudiado, traducido e interpretado, sino imitado. ${ }^{14}$ Su heroísmo vital, además de servir como contrapeso a la poesía decadentista de cuño francés, fertilizará en ciertos casos la búsqueda de nuevas formas de expresión en el campo de la creación literaria. Así, por ejemplo, para Mariátegui "el dannunzianismo sobre todo fue un fenómeno de irresistible seducción para el estado de ánimo rubendariano" (Mariátegui, 1950). ${ }^{15}$ Este canto de sirena, según Pedro Henríquez Ureña, es atribuible al hecho de que en la obra de D'annunzio se encuentra la marca peculiar de los latinos, su sensualismo, y nadie como él ha realizado el deseo de José Enrique Rodó "de modelar 'con el cincel de Heredia' la carne viva de Musset” (Henríquez, 1960, p. 5). Pero, a pesar de su gran presencia entre estos escritores, D’Annunzio tiene poco contacto directo con el mundo hispanoamericano.

Quizá una excepción lo constituye su relación con Gómez Carrillo, debido a sus afinidades: ambos poseían personalidades ególatras y compartían aficiones comunes, además de que laboraban en los medios periodísticos parisinos. Durante uno de sus viajes a Buenos Aires, a pregunta expresa de

\footnotetext{
${ }^{14}$ Por ejemplo, el escritor, ensayista y representante diplomático ecuatoriano Gonzalo Zaldumbide (1882-1965) publica su estudio La evolución de Gabriele D'Annunzio, en 1909.

${ }^{15}$ José Carlos Mariátegui, "La influencia de Italia en la cultura Hispano-Americana", Variedades, 25 de agosto de 1928, Lima.
} 
un periodista, Marinetti, "poeta italiano de lengua francesa", ${ }^{16}$ declara que Gómez Carrillo era un "viejo amigo" suyo, del cual "había sido su padrino y su ahijado en dos duelos" (Gasió, 2011, p. 121). Bellini afirma que Gómez Carrillo era, efectivamente, "amigo estimado" del poeta, "así como [el mismo Carrillo] lo era de Marinetti” (Bellini, 1982, pp. 253-254). De esta relación, el mismo Gómez Carrillo dejará testimonio en "En Roma con D’Annunzio” (Gómez, 1922, p. 291). Luego también, Amado Nervo, en un escrito en el que analiza las nuevas tendencias en el campo del arte y de la literatura, anota: "Los marinetistas haciendo todo tipo de contorsiones literarias para lograr un poquito de singularidad vana. Aquí esta ahora el amigo Marinetti con su futurismo pasado por agua, en el que sólo cree Enrique Gómez Carrillo, si es que Enrique Gómez Carrillo cree en alguna cosa” (Nervo, 2019).

Por su parte, Consuelo Suncín (1901-1978), la viuda de Gómez Carrillo, en la última fase de su vida, confirma en sus memorias que el poeta italiano era uno de los amigos que su esposo más frecuentaba. Luego del fallecimiento de Gómez Carrillo, Consuelo se convierte en Consuelo Suncín Sandoval, Condesa de Antoine Saint-Exupéry, al contraer nupcias con el autor de El principito. Posterior a la desaparición en los Andes del escritor piloto, según sus propias declaraciones, Consuelo se ligará sentimentalmente a Gabriele D’Annunzio (Carbonel y Martínez, 2010).

Sin pretender elaborar siquiera un esbozo de retrato, de los que hay tantos y tan completos (algunos de ellos ciertamente hagiográficos) ${ }^{17}$ en los estudios mariateguianos ${ }^{18}$ únicamente destacaremos aquí algunos elementos que nos permitan entender mejor el propósito del presente escrito. A grandes rasgos es preciso evocar que el joven Mariátegui ingresa al diario El Tiempo, en Lima, en 1916. Tres años más tarde, junto a César Falcón, funda el periódico La Ra-

${ }^{16}$ Rubén Darío, "Marinetti y el futurismo”, La Nación, 5 de abril de 1909.

${ }_{17}$ En los escritos sobre Mariátegui había sido una especie de tradición. Razón por la cual Robert Paris (1966, pp. 1065-1072) saluda como obra más objetiva, al mismo tiempo que señala deficiencias, el trabajo de Guillermo Rouillon (1968).

${ }^{18}$ A título de ejemplo: John M. Baines (1972); Michael Löwy (1987); Antonio Melis (1992, pp. 521-528); Estuardo Núñez (1994; 1964, pp. 179-197); Robert Paris (1966, pp. 1065-1072; 1961, pp. 3-13; 1981). 
zón (1919), lo cual coincidió temporalmente con un conjunto de huelgas de trabajadores en pro de la jornada de ocho horas. Por considerar que La Razón es opositor al gobierno, el presidente Leguía conmina a las dos cabezas visibles del periódico a alejarse del país. Frente a la disyuntiva de desoír la velada advertencia o tomarle la palabra, aceptan marcharse como corresponsales ("propagandista en el exterior") a Europa. César Falcón eligió España; Mariátegui, Italia.

Es también conocido que ambos decidieron viajar juntos y se embarcaron en el puerto de Callao ( 8 de octubre de 1919). Luego de una breve escala en Nueva York, llegaron a Francia el 10 de noviembre. En París se alojaron 40 días en el Barrio Latino, al final ellos se marcharon hacia la península itálica, ingresaron por Génova y se detuvieron en Milán, Turín y Pisa, en diciembre de 1919. Para Mariátegui ese fue el comienzo de una estancia en Italia (hasta marzo de 1923) decisiva para su formación ideológica, política y cultural, durante la cual entró en contacto con el pensamiento marxista y cimentó sus convicciones revolucionarias. ${ }^{19}$ Los artículos que escribió y envió para $\mathrm{El}$ Tiempo de Lima a lo largo de este periodo fueron reunidos y publicados posteriormente en forma de libro con el título Cartas de Italia (1975), de enorme importancia para comprender los fundamentos de su pensamiento.

En Italia, Mariátegui será testigo de la consolidación del fascismo, que con el sostén de la monarquía, los militares y los grandes propietarios agrarios e industriales, hace frente a la izquierda y a las conquistas parlamentarias obreras. Desde su arribo, a través del prisma de la prensa -principal, pero no exclusivamente, de L'Ordine Nuovo, Avanti, Il Soviet, Critica Sociale y, posteriormente, La Rivoluzione Liberale (a partir de febrero de 1922)- se informa y amplía su conocimiento de los grandes acontecimientos que agitan a Italia, al continente y al mundo: las ocupaciones de tierra en la península (Legh Rosse y Leghe Bianche), la insurrección en Hungría, las luchas obreras alemanas, el combate por la independencia en Irlanda, la revolución rusa. De hecho, el llamado "bienio rojo" culmina con el episodio de la ocupación de las fábricas FIAT, en agosto-septiembre de 1920, como veremos líneas más adelante.

Para los propósitos del presente escrito, sólo nos focalizaremos en el primero de los órganos de prensa antes mencionados, por constituir una de

${ }^{19}$ Una reciente aproximación al viaje de Mariátegui en Italia, enfocada a su formación intelectual, se encuentra en Gianandrea Nodari (2018, pp. 147-181). 
sus fuentes más importantes de información ${ }^{20}$ y de inspiración; haciendo hincapié tanto en la experiencia turinesa de democracia obrera como en la figura de Piero Gobetti (1901-1926), ${ }^{21}$ por su impronta (al lado de Croce, Papini, Tilgher, George Sorel, Barbusse y, claro está, Marx) en la formación ideológica y política de Mariátegui. L’Ordine Nuovo, Rassagna Settimanale di Cultura Socialista, había sido creada por Antonio Gramsci, Angelo Tasca (ambos 28 años), Humberto Terracini (24 años) y Palmiro Togliatti (26 años), en mayo de 1919, en Turín, sede de la FIAT y núcleo industrial del país. Desde la visita de Rubén Darío en 1900 hasta el presente, la FiAT había pasado de 450 a 10000 obreros que laboraban en sus instalaciones turinesas (Castronovo, 2005, p. 32).

En un primer momento, los redactores de la revista privilegiaron el aspecto cultural en la lucha revolucionaria y la necesaria preparación de la revolución, entendida como proceso capaz de construir la unidad entre las masas y los intelectuales. En un segundo tiempo, en continuidad con el proyecto anterior, la revista buscaba convertirse -y lo logró- en el portavoz del movimiento de los Consejos de Fábrica, vistos como el medio de realización de la democracia obrera, premisa de un futuro estado proletario. La especificidad del nuevo órgano de prensa consiste en haber sido la única publicación del movimiento obrero turinense.

La experiencia seminal de los Consejos de Fábrica corresponde al periodo de ocupación de fábricas, cuya máxima intensidad se produce, al mismo tiempo que culmina en derrota, en agosto-septiembre de 1920, aunque desde fines de junio la situación en la parte septentrional de Italia era ya objetivamente revolucionaria. La Torino, que había recibido a Mariátegui a vuelta de año (1919-1920), era en ese entonces la única ciudad con aspiraciones a convertirse en el Petrogrado italiano. El pensador peruano recordará después la constitución de los comisarios de fábrica (Comitato di Studio dei Consigli di Fabbrica Torinesi) llevada a cabo en la oficina metalúrgica de la Brevetti-Fiat, así como la cuestión de la toma de poder revolucionario que estaba al orden del día. En efecto, compuesto por varios grupos de izquierda -a la cabeza de

${ }^{20}$ Información, no obstante, deficitaria, como no podía ser de otra manera, debido a la distancia y a la falta de acceso a fuentes originales. Con todo y esos bemoles, no hay punto de comparación con la información a la que Mariátegui hubiera podido tener acceso a través de la prensa en Perú.

${ }^{21}$ Mariátegui consagrará posteriormente tres artículos a Gobetti, publicados en Mundial, entre julio y agosto de 1929, luego reagrupados en El alma matinal: "Piero Gobetti" (12 de julio), "La Economía y Piero Gobetti” (20 de julio) y "Piero Gobetti y el Risorgimento" (12 de agosto). 
Antonio Gramsci-, los comisarios no sólo libraban una batalla por horarios o salarios, sino que defendían el principio según el cual el gobierno de las fábricas debería estar en manos de la clase obrera, e igualmente que el orden del trabajo y de la producción debería ser controlado por los productores (obreros manuales, técnicos e intelectuales): se trataba de una revolución in statu nascendi.

Por ser parte de los actores y por encontrarse en primera línea, L'Ordine Nuovo cubrió con información de primera mano lo que allí ocurría. Tales acontecimientos evidenciarán la ruptura insalvable al interior de las fuerzas socialistas (revolucionarios, maximalistas y reformistas). La escisión se formaliza en el XVII Congreso Nacional del Partido Socialista Italiano, en Livorno, efectuado del 1 al 21 de enero de 1920, año en el que Gramsci figura entre los fundadores del Partido Comunista. Mariátegui, quien asiste a este congreso, recordará más tarde que la razón principal de tal ruptura había sido ideológica y que, de las tres tendencias en presencia, el Comintern había hecho suyos los puntos de vista de la fracción minoritaria comunista (Mariátegui, 1975, p. 93). Según Anna Chiappe, es en el curso de estas jornadas - probablemente en el Teatro Goldoni o en el San Marco- donde continuarían las sesiones de la fracción comunista, en las que Mariátegui ve y escucha a Gramsci durante sus intervenciones. ${ }^{22}$ En todo caso, el conocimiento que Mariátegui tiene del ordinovismo de Gramsci y de Gobetti no se limita a su paso por la capital del Piemonte o Livorno. Con un tiraje de 30000 ejemplares, impresos en Turín y su provincia, así como en Lombardía, el diario se difundía ampliamente y podía adquirirse con regularidad en numerosos puntos de distribución en las principales ciudades de Italia (Viglongo, 2017, p. 17).

Directamente o a través de las observaciones de Gramsci, la lectura de L'Ordine Nuovo es el punto de encuentro entre Mariátegui y Piero Gobetti, ${ }^{23}$ piedra angular en la concepción del proletariado que el pensador peruano adoptará y adaptará a la realidad concreta de su país natal y a la historia y a la cultura americana. Sin ser comunista, Gobetti es amigo de Gramsci y de los comunistas de su entorno, y colabora como crítico de teatro y literario en

22 "Anna Chiappe rememora su vida junto a José Carlos Mariátegui”, entrevista por Víctor Campos, Caretas, Lima, 2 de mayo de 1989. Recuperado de https://cortinasdehumo.wordpress.com/2016/11/27/anna-chiappe-rememora-su-vida-junto-a-jose-carlos-mariategui/

${ }^{23}$ Los trabajos que se han centrado u ocupado en parte de la relación entre Mariátegui y Gobetti son: Treves (1946); Paris (1961, pp. 3-13); Núñez (1964, pp. 179-197); Casetta (1967-1977, pp. 53-106); Melis (1979). Más recientemente, Beigel (2005). 
la revista. ${ }^{24}$ De pensamiento liberal, enmarcado en los horizontes de Keynes y John Stuart Mill, pero crítico del Estado italiano, está persuadido que la revolución o es portadora de libertad o se transforma pronto en su opuesto; por tanto, una revolución o es liberal (en el sentido de liberadora) o no es una revolución. También piensa que, si un proceso revolucionario debe suscitarse, este será guiado por el movimiento obrero, no por la burguesía que, entregándose al fascismo, demostraba (en Italia) haber agotado su misión histórica (Gobetti, 1996). Asimismo, estima -en su posición de resuelto adversario de todo programa de socialización de los medios de producción- que "el experimento marxista" en Rusia había fracasado, porque el juicio ético-político no coincide con el económico; en todo caso, había sido una confirmación del liberalismo, lo cual constituye para él una paradoja: "La ironía de la historia es que los primeros intereses burgueses, luego de tantos discursos de civilidad mística y desinteresada, se han creado en Rusia en nombre del marxismo"(Gobetti, 1997, p. 425). Sin embargo, su abierta simpatía por la obra de Lenin y, aún más, de Trotsky, era explícita.

Su formación como estudiante en la Universidad de Turín estuvo marcada por su maestro el economista Luigi Einaudi e influida por el pensamiento de Benedetto Croce y Giovanni Gentile. En la atmósfera del biennio rosso, en la que los liberales no eran ciertamente revolucionarios y los revolucionarios eran todo menos liberales, a causa de su postura, distante de la marxista de Gramsci, Gobetti fue rudamente criticado por Palmiro Togliatti en las mismas columnas de L'Ordine Nuovo (mayo de 1919). Crítica que también pudo haber obedecido colateralmente a los lineamientos de la Tercera Internacional Comunista, creada en Moscú tres meses antes, a la cual L'Ordine Nuovo estaba adherida y era portavoz (hasta 1924). Su labor consistía en depurar los elementos reformistas dentro del Partido Socialista de Italia.

En su reflexión y desarrollo del pensamiento liberal, que se avecinaba a una interpretación no ortodoxa del marxismo, Gobetti se preguntaba y trataba de resolver la cuestión fundamental relacionada con el proceso de formación de la voluntad colectiva - "el problema de los problemas", según Gaetano Salvemini-; es decir, cómo formar una nueva clase política capaz de derrotar y sustituir el dominio de la burguesía italiana. La respuesta consistía en preparar cultural y políticamente nuevos cuadros ligados a las masas populares

${ }^{24}$ Gramsci (1972) dirá de él: "no era un comunista y probablemente nunca lo hubiera sido, pero que había comprendido la producción social e histórica del proletariado” (pp. 376-377). 
aptos para conducir al país luego de la caída del fascismo; la política debe ser realizada en forma de educación. Con este objetivo, Gobetti puso en marcha un movimiento de acción ligado a la actividad periodística y editorial, materializada -además de su Energie Nove (1918-1920) y su colaboración con L'Ordine Nuovo (1919-1920) - en Revoluzione Liberale (febrero de 1922-noviembre de 1925), la revista cultural quincenal Il Barretti (diciembre 1924-enero 1925) y la casa editorial Piero Gobetti Editore. ${ }^{25}$ La revista de oposición al fascismo, a la cual -como señala Robert Paris (1961, p. 9)- Mariátegui es "un asiduo y atento lector", Revoluzione Liberale no tarda en ser intervenida por el comisario de la policía de Torino, quien seguía las instrucciones de Mussolini con el fin de impedir al joven talentoso toda actividad editorial, incluso las publicaciones periódicas, en enero de 1925. Para proseguir su combate, Gobetti se marchó a París, donde fallece en un hospital a los 25 años, el 11 de febrero de 1926, tres meses antes del arresto y el encarcelamiento de su amigo Gramsci por el mismo régimen contrarrevolucionario.

En consideración a los valores morales y la coherencia intelectual que Gobetti sostuvo a lo largo de su breve existencia, Mariátegui declaró haber experimentado hacia su persona una "afectuosa asonancia", y-como subraya Robert Paris-Gobetti será "un punto constante de referencia, tanto en el plano de la concepción literaria como en el de la política y la metodología e incluso, se puede decir, de la concepción ética de la vida" (Paris, 1961, p. 6).

Para comenzar a cerrar el presente apartado, estableceremos a grandes líneas ciertos paralelos entre ambos pensadores perseguidos políticos y muertos jóvenes. ${ }^{26}$ En torno al mito de la revolución social como expresión de la voluntad, no del intelecto, idea central en la atmósfera del pensamiento de la época (en cuya reflexión lanzan las bases Georges Sorel, Henri Bergson, Romain Rolland y Ortega y Gasset), Mariátegui afirma: "La fuerza de los revolucionarios no reside en ciencia sino en su fe, su pasión, su voluntad. Es una fuerza religiosa, espiritual, mística" ${ }^{27}$ Por su parte, Gobetti (1969) sostuvo que el "discurso revolucionario se inscribe en una matriz de carácter mesiánico",

${ }^{25}$ Gobetti crea la casa editorial en marzo de 1923. En dos años publica cien libros de autores antifascistas, pero también liberales, católicos, simpatizantes del movimiento obrero, socialistas, sindicalistas revolucionarios e incluso el "fascista" Curzio Malaparte. Luigi Einaudi y Gaetano Salvemini, sus maestros, publicarán allí Le lote del lavoro (1924) y Dal patto di Londra alla pace di Roma (1925), respectivamente. Citado en Polito (2019, pp. 206-207).

${ }^{26}$ Sobre la sinonimia entre Gramsci y Mariátegui, véase Aricó (1978).

${ }^{27}$ José Carlos Mariátegui, "El hombre y el mito", Variedades, 11 de octubre de 1924. 
y que la lucha contra el fascismo, "antes que política, es de naturaleza moral, tiene un valor religioso"; por tanto, añade, "mi lugar está necesariamente en la parte de más religiosidad y voluntad de sacrificio. La revolución hoy se sitúa en todo su carácter religioso" (pp. 419-420). En otro momento, manifiesta que "el socialismo y el comunismo no son ideales que persigue una sociedad, sino que tienen una función histórica como mitos de acción" ${ }^{28}$ Ambos comparten también un rechazo a la ideología iluminista del progreso (que crea la ilusión peligrosa de felicidad por obra del orden imperante) y, desde perspectivas diferentes, una crítica aguda contra la burguesía. Asimismo, los dos se entregaron a la tarea de organizadores de cultura, ${ }^{29}$ entendiendo la necesidad de vincular el combate político con la literatura y el arte; impulso en el cual la fuerza motriz del cambio lo constituye la prensa, cuya función principal es elevar el nivel cultural de la clase trabajadora.

\section{A MANERA DE CONCLUSIONES}

El punto de partida de este trabajo consistente en interrogarnos sobre las relaciones de los tres autores aludidos con la atmósfera cultural e intelectual italiana durante sus respectivas estancias en Europa, y nos marcó el camino para indagar sobre nuestros supuestos iniciales. En esta conexión entre actores y componente histórico, en los tres grandes apartados que integran el cuerpo principal del presente texto, hemos seguido las pistas de Rubén Darío por diferentes ciudades de Italia, pasado por el tamiz las experiencias de Gómez Carrillo y, en un tercer momento, observado de cerca aspectos del "momento mariateguista" en Italia,

De los protagonistas analizados, los tres recorrieron o realizaron estancias de breves a prolongadas en el Bel Paese y escribieron e interpretaron -al mismo tiempo que contribuyeron a difundir masivamente en el mundo hispanoamericano- su historia, su arte, su literatura, sus mitos y su realidad política. A pesar de la común francofilia de Rubén Darío y Gómez Carrillo, admiración no tan presente en el caso del escritor peruano, también los tres

${ }^{28}$ Piero Gobetti, "Guerra agli apolitici”, La Rivoluzione Liberale, año III, núm. 10, 4 de marzo de 1924, p. 40.

${ }^{29}$ Mariátegui funda la casa editorial Minerva (1925), la revista mensual Amauta (1926), organiza Central General de Trabajadores de Perú, funda el Partido Socialista del Perú y publica sus 7 ensayos sobre la realidad peruana (1928). 
compartieron una fascinación por el arte y el mundo del pensamiento y de la cultura italiana; seducción y conocimiento evidenciados en sus publicaciones respectivas. De sus contemporáneos, los tres conocieron lo esencial de las obras de D'Annunzio y de Marinetti, por haber recibido su influencia o, en el caso de Gómez Carrillo, por haber cultivado relaciones de amistad. Si Darío y Mariátegui comprenden y admiran la obra del histriónico autor de Il piacere, su postura será crítica y sin halagos. ${ }^{30}$

El viaje a Italia guardará un significado diferente y especial: elevado al rango de realización de un sueño, o bien, en lo concerniente al pensador peruano, la atmósfera ideológica y política se encuentra propicia para insertarse de manera original y crítica en el pensamiento marxista. No obstante, si bien a partir de inquietudes diferentes e incluso divergentes, otro punto de convergencia es la idea del viaje espiritual y del viaje a través de la geografía. Gómez Carrillo, por ejemplo, se autodefine como "El cronista errante" y se considera "ciudadano del mundo"; Rubén Darío es un desarraigado "por excelencia", y el Amauta, en continuo movimiento, un hombre que decide ver Italia con sus propios ojos, sin lentes capciosos de la erudición, sin literatura. ${ }^{31}$

De igual manera, hemos visto cómo en los escritos de Darío el culto del yo, la exaltación y la subjetividad son elementos con frecuencia presentes en su búsqueda de una realidad más allá del mundo real. En el caso de Gómez Carrillo, por la fuerza de las circunstancias testigo y narrador del conflicto armado durante su estadía en Italia, sus artículos periodísticos, precisos y bien documentados, contribuirán a desvanecer la reputación de superficialidad que empañaba su obra, trivialidad sobre la cual el autor de los Siete ensayos fundaba su juicio. En cambio, en Mariátegui, L'Ordine Nuovo y, en particular, la obra de Gobetti, constituyen unos de los puntos de mayor densidad interpretativa y de propuesta creativa para la acción, cuya reflexión está contenida en Cartas de Italia. Sin embargo, no es posible hablar de una influencia directa. Mariátegui bebió de fuentes diversas, tomó un poco de todas partes; aunque las afinidades entre Gobetti y Mariátegui son numerosas, puesto que compartían intereses comunes. En Italia asimilará igualmente la cosmovisión y aspectos del pensamiento de autores diversos: Bergson (reacción al positi-

${ }^{30}$ Mariátegui (1950) dirá de él: "un gran poeta y gran histrión, merece ser considerado como el producto genuino del suelo y de la raza italiana. Pero D’Annunzio no es más que un modelo de una serie interminable".

${ }^{31}$ En respuesta a la pregunta de cuál es su afición predilecta, Mariátegui (1994) responderá: "Viajar. Soy un hombre orgánicamente nómada, curioso e inquieto" (p. 1392). 
vismo), Georges Sorel (rechazo al determinismo que privilegia la estructura económica a la acción revolucionaria), Miguel de Unamuno (la humanidad y la religiosidad, el ideal de Don Quijote), el surrealismo (transformar el mundo, cambiar la vida) y -en apariencia diametralmente opuesto- Nietzsche (asimilación original de motivos nietzscheanos dentro de su concepción revolucionaria) (véase Ibáñez, 2011, pp. 11-24).

\section{LISTA DE REFERENCIAS}

Aricó, J. (1978). Mariátegui y los orígenes del marxismo latinoamericano. México: Cuadernos del Pasado y Presente.

Baines, J. M. (1972). Revolution in Peru: Mariategui and his myth. Montgomery: Alabama University.

Beigel, F. (2005). Una mirada sobre otra: el Gramsci que conoció Mariátegui. Estudios de Sociología, 18/19, 23-49.

Bellini, G. (1982). Storia delle relazioni letterarie tra l'Italia e l'America di lingua spagnola. Milano: Cispalpino-Goliardica.

Carbonel, M. H. y Martínez, M. F. (2010). Consuelo Suncín Sandoval, condesa de Antoine Saint-Exupérie. Une mariée vêtue de noir. Mónaco: Édition du Rocher.

Casetta, G. (1967-1977). L'esperienza italiana di Mariátegui. Elementi della formazione culturale e ideologica di un marxista latinoamericano. Mezzosecolo. Materiali di Ricerca Storica, Annali, 2, 53-106.

Castronovo, V. (2005). Fiat. Una storia del capitalismo italiano. Milán: Rizzoli Editore.

Chang-Rodríguez, E. (1982). La obra literaria juvenil de José Carlos Mariátegui. Revista de la Universidad Católica, 11/12, 175-227.

Colombi, B. (1997). Peregrinaciones parisinas: Rubén Darío. Orbis Tertius, 2(4). Recuperado de https://www.orbistertius.unlp.edu.ar/article/view/OTv02n04a09

Darío, R. (1900). Azul (segunda edición). Guatemala: La Unión.

Darío, R. (1901). Peregrinaciones (pról. de Justo Sierra). París: Librería de la Viuda de Ch. Bouret.

Darío, R. (1904). Tierras solares. Madrid: Leonardo Williams Editor.

Darío, R. (1915). La vida de Rubén Darío escrita por él mismo. Barcelona: Casa Editorial Maucci. Recuperado de www.cervantes.virtual.com

Fernández Ordoñez, R. (2016). Dime con quién andas y te diré qué escribes. La amistad de Gómez Carrillo y Rubén Darío. Universidad Francisco Marroquí-Departamento de 
Educación. Recuperado de https://educacion.ufm.edu/dime-con-quien-andas-yte-dire-que-escribes-la-amistad-de-gomez-carrillo-y-ruben-dario/

Gasió, G. (ed.) (2011). Que sean libros en blanco. En torno a una encuesta del diario Última Hora sobre "el libro nacional y su venta" (febrero junio de 1926). Buenos Aires: Teseo.

Gobetti, P. (1923). Il problema della civilità russa. Palermo: L'Ora.

Gobetti, P. (1969). La Russia dei soviet, Rivista di Milano, 20 de febrero de 1922. En P. Gobetti, Scritti storici, letterari e filosofici. Torino: Einaudi.

Gobetti, P. (1996). Al nostro posto. Scritti politici da "La Rivoluzione Liberale". Arezzo: Lìmina.

Gobetti, P. (1997). Scritti politici. Torino: Einaudi.

Gómez Carrillo, E. (1922). Crónicas, obras completas (vol. xxIV, libro quinto). Madrid: Mundo Latino.

Gómez Carrillo, E. (1925). El evangelio del amor. Madrid: Renacimiento.

Gramsci, A. (1972). La constituzione del Partido Comunista. Turín: Einaudi.

Henríquez Ureña, P. (1960). D’Annunzio, el poeta. En Ensayos críticos. México: Fondo de Cultura Económica.

Ibañez, A. (2011). Mariátegui: un marxista nietzscheano. Espiral, 8(22), 11-24.

Löwy, M. (1987). El marxismo romántico de Mariátegui. Márgenes, 2.

Mariátegui, J. C. (1950). El alma matinal y otras estaciones de hoy. Lima: Empresa Editora Amauta.

Mariátegui, J. C. (1975). Cartas de Italia (3 ed.). Lima: Amauta.

Mariátegui, J. C. (1994). Obras completas (t. I). Lima: Amauta.

Massimo Prossio, P. (2007). Stendhal ed altri viaggiatori a Torino. Il viaggio letterario da Tasso a Nietzsche. Turín: CIRvi.

Melis, A. (1979). Mariátegui, primer marxista de América (Cuadernos de Cultura Latinoamericana, 95). México: Universidad Nacional Autónoma de México.

Melis, A. (1992). Perù e Italia immagini incrociate. Bologna: Ravenna Longo Ed.

Nervo, A. (2019). El "unanismo". En La lengua y la literatura. Obras completas (vols. XXI-XXIII). Recuperado de https://www.cervantesvirtual.com/obra/amado-nervo

Nietzsche, F. (2008). Lettere da Torino (Piccola Biblioteca, 569). Torino: Adelphi.

Nodari, G. (2018). Mariátegui antes de Mariátegui. El viaje a Italia y el fin de la "edad de piedra”, 1919-1923. Izquierdas, 39, 147-181. DoI: https://dx.doi.org/10.4067/ S0718-50492018000200147

Núñez, E. (1964). José Carlos Mariátegui y su experiencia italiana. Cuadernos Americanos, 6, 179-197.

Núñez, E. (1994). La experiencia europea de Mariátegui. Lima: Amauta.

Paris, R. (1961). Mariáteggui e Gobetti. Quadern, 1. 
Paris, R. (enero-febrero, 1966). José Carlos Mariátegui: Une bibliographie; quelques problèmes. Annales, Economies, Civilisations, 1065-1072.

Paris, R. (1981). La formación ideológica de José Carlos Mariátegui. México: Editorial Siglo XXI.

Polito, P. (2019). L'Utopia della rivoluzione, La rivoluzione liberale di Piero Gobetti. Torino: Arias Edizione.

Rouillon, G. (1968). Bibliografía de José Carlos Mariátegui. Lima: Universidad de San Marcos.

Sierra, J. (1901). Prólogo. En R. Darío, Peregrinaciones. París: Librería de la Viuda de Ch. Bouret.

Treves, R. (1946). Piero Gobetti y la revolución liberal. Revista Babel, Santiago de Chile.

Ulner, A. R. (1974). Enrique Gómez Carrillo en el modernismo: 1889-1896. (Tesis inédita de doctorado). Universidad de Missouri, Columbia.

Vargas Vila, J. M. (1917). Rubén Darío. Madrid: V. H. de Sanz Calleja.

Verrecchia, A. (1978). La catastrofe de Nietszche a Torino. Turín: Einaudi.

Viglongo, A. (2017). Gramsci a Torino (prefazione di Angelo d'Orsi). Turín: Andrea Viglongo \& C. Editori Torino. 